\title{
The role of cotton in respiratory symptoms in the fall
}

\author{
James A. Tarbox MD
}

\begin{abstract}
During the fall, many people in West Texas have worsening respiratory symptoms while cotton is being harvested and ginned. A common complaint is that cotton itself is to blame for nasal and pulmonary manifestations. Allergic sensitivity to cotton is actually quite uncommon, even in workers in textile and processing plants. Mold, especially Alternaria and Aspergillus species, are occasionally found in cotton crops and can be a source of allergens and mycotoxins. Lipopolysaccharides (LPS) from bacteria could have a role in reduction of FEV $V_{1}$ in byssinosis. Enterobacter in cotton dust possesses highly potent LPS which can elicit a strong inflammatory response in workers. Defoliants, desiccants, pesticides, fertilizers and exhaust fumes are also potential irritants of the respiratory tract. Cotton alone is not the primary source of illness during autumn months. A multitude of allergens, microbes, irritants, and chemical agents that co-exist or are a byproduct of cotton harvesting and ginning are potential contributors to respiratory disease.
\end{abstract}

Keywords: cotton, respiratory, fall, allergy, harvest

Cotton is the cash crop for West Texas as well as one of its strongest economic drivers. The South Plains represents the largest cotton producing area in the world, exceeding 3 million acres some years. ${ }^{1}$ Every fall, the crop must be harvested and ginned. During this time, I have an increase in patients who complain that their allergies are a lot worse. This leads to a discussion of irritants versus allergens. This distinction is important because there are a lot of irritants in the air during harvesting and ginning, but far fewer allergens.

Irritants are substances that cause a range of symptoms to everyone after a single exposure. These include smoke, odors, fumes, and changes in temperature or pressure. While most weak irritants cause

Corresponding author: James Tarbox Contact Information: James.tarbox@ttuhsc.edu DOI: 10.12746/swrccc.v5i21.422 short lived symptoms, recurrent exposure can have lasting effects. Vasomotor rhinitis, a non-allergic manifestation of runny nose and congestion, can occur with previously mentioned irritants along with hot or spicy meals and medication.

An allergic reaction occurs when your body responds to a protein in a manner beyond a normal response in the general population. For example, you may have a runny nose in the spring when trees are pollinating. An example of a more severe reaction would include a penicillin-derived antibiotic causing throat swelling or a drop in blood pressure.

When I first arrived at TTUHSC to start my allergy and immunology clinic, I included cotton linters on my routine allergy skin test panel which also includes 50 other common environmental allergens. I theorized that with all the cotton fields in the area, this would be a common allergen. In the two years this was on our panel, only a couple of patients tested positive. Furthermore, only one farmer who was exposed to cotton regularly was sensitive. This was pretty 
surprising to me at the time. Then the major manufacturers of allergens for immunotherapy and patient testing in the United States decided to stop selling cotton linters extract as it was not profitable for them.

If one evaluates the intricacies of cotton linters, the paucity of positive test results starts to make sense. The cotton linter is the fiber connected to the seed after cotton lint (normal length fiber) is removed during ginning. These bits of fuzz stay connected to the cottonseed and are removed later by a delinting machine. A study of 255 workers from four cottonseed crushing mills in the southern U.S. evaluated their respiratory health and atopy. ${ }^{2}$ They were divided into groups: primarily exposed to linters dust, non-linters product dust, or mixed. About $8 \%$ of the patients continuously exposed to linters dust were reactive to cotton linters on skin test, $4 \%$ had a positive skin test with some exposure to linters dust, and $0 \%$ with no linters exposure. Linter workers who were atopic also had a significant decline in $\mathrm{FEV}_{1}$. Fusarium mold showed similar increased reactivity in the linters group. Fusarium is a frequent source of contamination in raw cotton fibers. ${ }^{3}$ Once linters are obtained, they are used in pillows, upholstery, hard plastic, ice cream, hot dog casings, toilet paper, and paper currency. 4

Other molds found specifically in preharvest cottonseeds in West Texas are the Alternaria species and Aspergillus niger. ${ }^{5}$ While the concentration of seeds with these molds was very small, $2 \%$ and $4 \%$, respectively, both of these fungi could be potent sources of mycotoxins. Ochratoxin A is a mycotoxin produced by Aspergillus niger and potentially nephrotoxic. ${ }^{6}$ Mold also is a common cause of IgE-mediated allergic reactions which can be evaluated by skin prick testing. During the fall, the other major allergens in the air are weeds, especially ragweed and tumbleweed, and to a lesser extent grasses.

Byssinosis is a well described pulmonary disease that affects cotton workers in enclosed settings. Workers begin to have shortness of breath and chest tightness at the start of the work week (Monday phenomenon). After several more years, symptoms tend to be more severe and occur more regularly. Terpenoids and phenols present naturally in cotton and glucans in fungi may contribute to byssinosis. Endotoxins, lipopolysaccharides (LPS) from Gramnegative bacteria, have been extensively studied, and workers exposed to cotton dust with high concentrations of endotoxin had significantly decreased $\mathrm{FEV}_{1}{ }^{7}$ Enterobacter cloacae and Flavimonas oryzihabitans are two bacteria commonly found to contaminate cotton fibers in the U.S. Enterobacter has been shown to contain highly potent LPS and elicit a potent inflammatory response. ${ }^{8}$

While processing cotton can cause airway disease, immediate cutaneous reaction is very rare. A case report from Spain discussed a 24-year-old who for 3 years experienced itchy skin within minutes after wearing any cotton material. ${ }^{9}$ Symptoms would resolve within 20 minutes of cotton removal. She denied any occupational exposure. Skin prick test to cotton extract was positive with a $4 \times 4 \mathrm{~mm}$ wheal suggesting a Type I hypersensitivity reaction. Sanitary cotton rubbed on the forearm produced a well-defined, erythematous, pruritic patch. Immunoblotting showed $\lg \mathrm{E}$ reactivity to a protein subsequently identified as vicilin. This represents a unique cause of skin reactions from cotton.

Another case report from Texas involved a 39-yearold woman who experienced laryngeal edema and hoarseness during cotton ginning season. ${ }^{10}$ Her symptoms would improve upon leaving the area at this time and recur when she returned. Several allergy evaluations that included skin testing and radioallergosorbent assays were unable to determine the cause of her symptoms. Direct exposure of cotton near her face would cause total loss of voice, chest tightness, and difficulty breathing. Symptoms were partially relieved by nebulized isoproterenol hydrochloride. She underwent challenges to several volatile, aromatic compounds released by cotton and experienced symptoms to the following sesquiterpenes: $\beta$-bisabolol, $\beta$-caryophyllene, and $\beta$-caryophyllene oxide. As cotton matures before harvest, these substances manifest more in the air and could explain this patient's symptoms.

While adults experience a variety of pulmonary illnesses when exposed to cotton dust, few studies have evaluated the impact on children. Kingston 
and Parchman evaluated whether children living in rural, cotton-producing counties were at higher risk for asthma compared to counties with limited cotton exposure. ${ }^{11}$ Fifth-graders from three cotton producing counties and four non-cotton producing counties in West Texas were given surveys in late November and early December of 2000 . This survey was based on the eight questions from the International Study of Asthma and Allergies in Childhood to assess the prevalence and severity of asthma. ${ }^{12}$ Children would take home the survey for their parents to complete- 288 surveys in cotton producing and 295 in non-cotton producing counties. The prevalence of wheezing in the previous year was $22.3 \%$ in cotton producing counties and $15.6 \%$ in non-cotton producing counties $(p=0.12)$. In cotton producing counties, $17 \%$ of children were diagnosed with asthma compared to $14 \%$ in non-cotton producing counties $(p=0.41)$. Thus, there was no significant difference in the overall rates of asthma in regions with or without cotton. Children in cotton regions, however, did have more frequent and severe symptoms. This study is confounded by having a higher prevalence of asthma in West Texas than the national prevalence estimated by the CDC of $6.4 \%$ in $1998 .{ }^{13}$

Many products used in cotton farming can irritate upper and lower airway symptoms, including defoliants, desiccants, exhaust fumes, pesticides and fertilizers. Furthermore, atopic patients appear at an increased risk of prolonged asthma symptoms after exposure to irritants for weeks to months. ${ }^{14}$ Their asthmatic symptoms are similar to a prolonged lower respiratory tract viral illness. Low level irritants also lead to a more pronounced response upon exposure to allergens. While skin testing and specific ImmunoCAP ${ }^{\circledR} \lg$ E blood tests are sensitive for environmental allergens (e.g., trees, grasses, weeds, mold, and dander), they are unfortunately not able to detect irritants.

In summary, Type I hypersensitivity allergic reactions to cotton are very uncommon. However, during harvesting and ginning season, people are exposed to many substances besides cotton, including pollutants, allergens, bacteria, viruses, mold, endotoxins, defoliants, pesticides and other materials that can aggravate nasal and respiratory symptoms. Cotton ginning tends to cause more occupational asthma. While living in an area with cotton farming is associated with some adverse effects, the crop is one of the major regional economic pillars associated with numerous jobs and used around the world in commercial goods and services.

Article citation: Tarbox J. The role of cotton in respiratory symptoms in the fall. The Southwest Respiratory and Critical Care Chronicles, 2017;9(21):44-47

From: Department of Internal Medicine, Texas Tech University Health Sciences Center, Lubbock, TX

Submitted: 6/7/2017

Accepted: 9/18/2017

Reviewer: Goutam Shome MD, PhD

Conflicts of interest: none

\section{REFERENCES}

1. Cotton Production Regions of Texas. Texas A\&M AgriLife Extension. (Accessed February 28, 2017, at http://cottonbugs.tamu.edu/cotton-production-regions-of-texas/).

2. Jones RN, Butcher BT, Hammad YY, Diem JE, Glindmeyer HW 3rd, Lehrer SB, Hughes JM, Weill H. Interaction of atopy and exposure to cotton dust in the bronchoconstrictor response. Br J Ind Med 1980;37:141-6.

3. Prindle B. The microbiology of textile fibers (cotton). Textile Res 1934;5:11-31.

4. Rivoli P. The Travels of a T-Shirt in the Global Economy. John Wiley \& Sons, 2005.

5. Simpson ME, Marsh PB, Merola GV, Ferretti RJ, Filsinger EC. Fungi that infect cottonseeds before harvest. Appl Microbiol 1973;26:608-13.

6. Bennett JW, Klich M. Mycotoxins. Clin Microbiol Rev 2003;16:497-516.

7. Castellan RM, Olenchock SA, Kinsley KB, Hankinson JL. Inhaled endotoxin and decreased spirometric values. An exposure response relation for cotton dust. NEJM 1987; 317:605-10.

8. Lane SR, Sewell RD. The bacterial profile of cotton lint from worldwide origins, and links with occupational lung disease. Am J Ind Med 2007;50:42-7.

9. González de Olano D, Subiza JL, Civantos E. Cutaneous allergy to cotton. Ann Allergy Asthma Immunol 2009; 102:263-4. 
10. Lefkowitz SS, Lefkowitz DL. A severe response to substances released from cotton. JAMA 1984;251:1835-6.

11. Kingston BJ, Parchman ML. The association between cotton and prevalence of rural childhood asthma. Tex Med 2003;99:61-5.

12. Asher MI, Keil U, Anderson HR, et al. International Study of Asthma and Allergies in Childhood (ISAAC): rationale and methods. European Respiratory Journal 1995;8:483-91.
13. Centers for Disease Control and Prevention, (CDC). Forecasted state-specific estimates of self-reported asthma prevalence-United States, 1998. MMWR Morb Mortal Wkly Rep 1998;47:1022-5.

14. Brooks SM, Hammad Y, Richards I, Giovinco-Barbas J, Jenkins K. The Spectrum of Irritant-Induced Asthma. Chest 1998;113:42-9. 